prognostic scoring system for predicting survival and leukemic evolution in myelodysplastic syndromes. J Clin Oncol 2007; 25:3503-10.

10. Niscola P, Vischini G, Tendas A, et al. Management of hematological malignancies in patients affected by renal failure. Expert Rev Anticancer Ther 2011;11:415-32.

\section{A case of myelodysplastic syndrome with a $\operatorname{der}(I ; I 8)(q|0 ; q| 0)$ translocation}

TO THE EDITOR: Whole-arm translocations are relatively rare cytogenetic aberrations in hematologic malignancies [1]. Mostly, these translocations are unbalanced and accompanied by genomic imbalances, such as trisomy and monosomy of each whole-arm of the 2 involved chromosomes. Until now, approximately 11 different unbalanced wholearm translocations have been reported as the sole recurrent abnormalities in hematologic malignancies: $\operatorname{der}(1 ; 7)(q 10 ; q 10)$, $\operatorname{der}(1 ; 14)(q 10 ; q 10), \operatorname{der}(1 ; 15)(q 10 ; q 10), \operatorname{der}(1 ; 18)(q 10 ; q 10)$, $\operatorname{der}(7 ; 12)(q 10 ; q 10), \operatorname{der}(13 ; 14)(q 10 ; q 10), \operatorname{der}(14 ; 21)(q 10 ; q 10)$, $\operatorname{der}(17 ; 18)(q 10 ; q 10), \operatorname{der}(1 ; 7)(q 10 ; p 10), \operatorname{der}(1 ; 7)(p 10 ; q 10)$, and $\operatorname{der}(9 ; 18)(\mathrm{p} 10 ; \mathrm{q} 10)[1]$.

Particularly, the $\operatorname{der}(1 ; 18)(\mathrm{q} 10 ; \mathrm{q} 10)$ translocation is very rare in hematologic malignancies. Only 3 cases of hematologic malignancy with $\operatorname{der}(1 ; 18)(\mathrm{q} 10 ; \mathrm{q} 10)$ translocations have been reported since the translocation was first described by Wan et al; each was a case of refractory anemia with excess blasts (RAEB), myeloproliferative disorder (MPD), and essential thrombocythemia (ET) [2, 3]. A few other cases including non-Hodgkin's lymphoma (NHL), pol- ycythemia vera, and primary myelofibrosis had $\operatorname{der}(1 ; 18)$ (q10;q10) translocations as a part of a more complex karyotype, but lacked detailed case descriptions [1, 4-6].

Three years ago, a 73-year-old woman was admitted to our hospital because of pancytopenia. Her complete blood cell count (CBC) showed a hemoglobin (Hb) level of 7.7 $\mathrm{g} / \mathrm{dL}$ with a mean corpuscular volume (MCV) of $105 \mathrm{fL}$ (reference, 80-99 fL), a platelet count of $58 \times 10^{9} / \mathrm{L}$, and a white blood cell (WBC) count of $2.29 \times 10^{9} / \mathrm{L}$ with $40 \%$ segmented neutrophils, $46 \%$ lymphocytes, $8 \%$ monocytes, and $3.9 \%$ eosinophils. The peripheral blood smear showed macrocytic erythrocytes without immature cells. At that time, a bone marrow (BM) biopsy was not performed. Theserum vitamin $\mathrm{B}_{12}$ level was $234 \mathrm{pg} / \mathrm{mL}$ (reference, 211-911 pg/mL) and the folate level was $>20 \mathrm{ng} / \mathrm{mL}$ (reference, 4.2-19.9 $\mathrm{ng} / \mathrm{mL}$ ). Despite vitamin supplementation therapy for 3 years, her pancytopenia did not improve. However, her general health status was sustained at a tolerable state. Three months ago, the patient was diagnosed as having gastric adenocarcinoma and underwent a total gastrectomy. At that time, her CBC still showed pancytopenia with the following blood markers: $\mathrm{Hb}, 9.1 \mathrm{~g} / \mathrm{dL} ; \mathrm{WBC}, 2.04 \times 10^{9} / \mathrm{L}$ (47.6\% segmented neutrophils, $40.8 \%$ lymphocytes, $6.5 \%$ monocytes, and $1.3 \%$ eosinophils), and platelets, $58 \times 10^{9} / \mathrm{L}$. The MCV was $102 \mathrm{fL}$ and the serum vitamin $\mathrm{B}_{12}$ level was $1,180 \mathrm{pg} / \mathrm{mL}$. The serum iron, total iron binding capacity, and ferritin levels were $114.1 \mu \mathrm{g} / \mathrm{dL}$ (reference, 29-164 $\mu \mathrm{g} / \mathrm{dL}$ ), 301 $\mu \mathrm{g} / \mathrm{dL} \quad$ (reference, 22-433 $\mu \mathrm{g} / \mathrm{dL}$ ) and $532.7 \mathrm{ng} / \mathrm{mL}$ (reference, 10-291 ng/mL), respectively. The reticulocyte level was $1.83 \%$ (reference, $0.5 \%-1.5 \%$ ). The BM was hypocellular with $38.6 \%$ myeloid cells, $37.0 \%$ erythroid cells, and $20.7 \%$ lymphocytes. The erythroid series were slightly increased and a mild dyserythropoiesis (megaloblastic changes, binuclarity, and nuclear buddings) was observed (Fig. 1A). Myeloid cells and megakaryocytes were un-

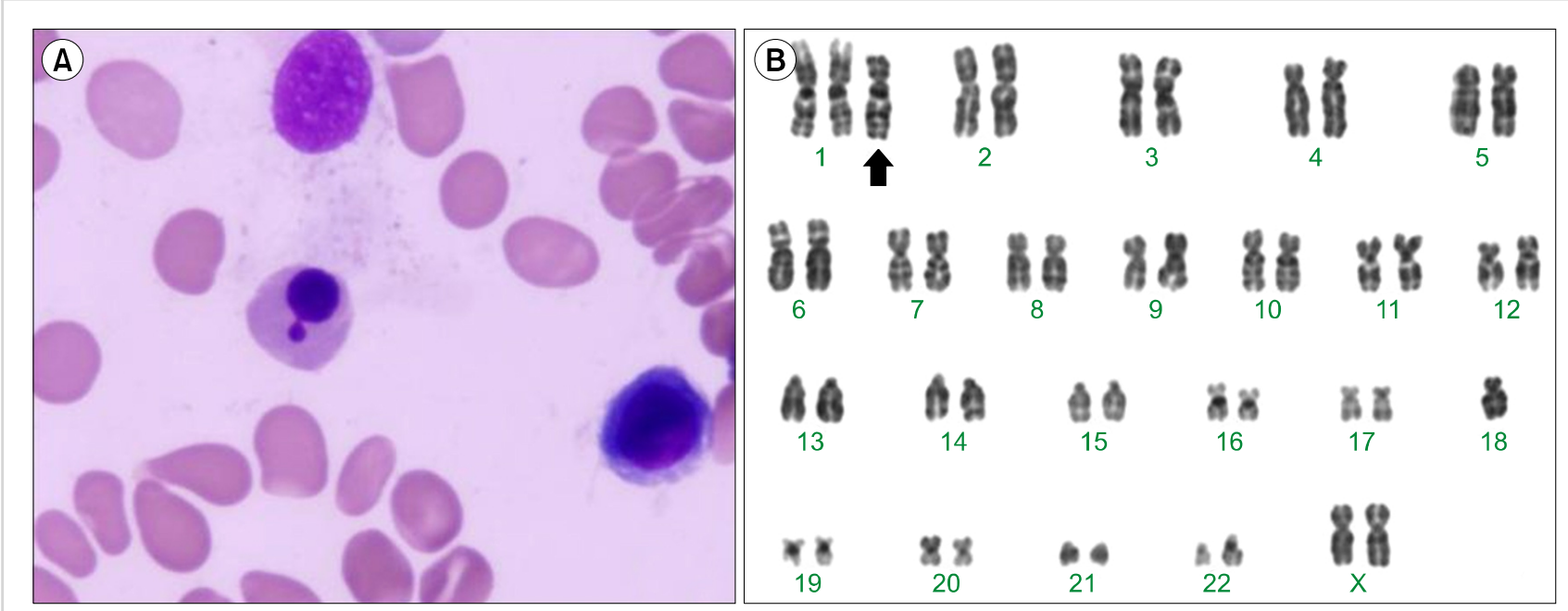

Fig. 1. (A) A nuclear-budding and megalocytic orthonormoblast representing dyserythropoiesis (Wright stain, $\times 1,000$ ). (B) G-banded karyogram of bone marrow cells. The arrow indicates the $\operatorname{der}(1 ; 18)(q 10 ; q 10)$ chromosome. 
Table 1. Reported cases with the der $(1 ; 18)(q 10 ; q 10)$ chromosomal abnormality.

\begin{tabular}{lccllll}
\hline Case No. & Age & Gender & Diagnosis & \multicolumn{1}{c}{ Karyotype } & \multicolumn{1}{c}{ Clinical characteristics } & \multicolumn{1}{c}{ Reference } \\
\hline 1 & 23 & M & RAEB & $44-46 . X Y,+1, \operatorname{der}(1 ; 18)(q 10 ; q 10)[\mathrm{cp} 3] / 46, X Y[5]$ & died1 month after diagnosis & Wan et al. [3] \\
2 & 65 & F & MPD & $46, X X,+1, \operatorname{der}(1 ; 18)(q 10 ; q 10)[12]$ & Stable during follow-up & Wan et al. [3] \\
3 & 75 & F & ET & $46, X X,+1, \operatorname{der}(1 ; 18)(q 10 ; q 10)[7] / 46, X X[13]$ & Stable for 1 month & Azuma et al. [2] \\
Our case & 76 & F & MDS-U & $46, X X,+1, \operatorname{der}(1 ; 18)(q 10 ; q 10)[5] / 46, X X[15]$ & Stable for 3 months & \\
\hline
\end{tabular}

Abbreviations: RAEB, refractory anemia with excess blasts; MPD, myeloproliferative disorder; ET, essential thrombocythemia; MDS-U, myelodysplastic syndrome, unclassifiable.

remarkable in morphology and number. BM iron was sufficient $(3+/ 5+)$. A BM cytogenetic study revealed the following chromosome abnormalities: 46,XX,+1,der(1;18)(q10;q10)[5]/ $46, \mathrm{XX}[15]$ (Fig. 1B). As a result of the BM findings and the clonal chromosomal changes, the patient was diagnosed as having unclassifiable myelodysplastic syndrome (MDS-U), according to World Health Organization classification system. Because of her old age and stable general condition, the patient is only receiving vitamin supplementation therapy and is scheduled forregular follow-up visits.

Although a $\operatorname{der}(1 ; 18)(q 10 ; q 10)$ translocation has been reported in a case of NHL, this translocationis mainly observed in myeloid disorders, primarily in myeloproliferative neoplasms. Moreover, 3 cases including our case had the $\operatorname{der}(1 ; 18)(\mathrm{q} 10 ; \mathrm{q} 10)$ translocation as the sole abnormality; this indicates that $\operatorname{der}(1 ; 18)(\mathrm{q} 10 ; \mathrm{q} 10)$ might be a primary change in myeloid diseases.

With unbalanced $\operatorname{der}(1 ; 18)(q 10 ; q 10)$ translocations, either trisomy $1 \mathrm{q}$ or monosomy $18 \mathrm{p}$ has been suggested to contribute to leukemogenesis. Trisomy 1q may contribute to leukemogenesis through a gene dosage effect as the region q25-q32 has been suggested to give rise to a proliferation advantage of the neoplastic clone in hematologic malignancies [7]. Monosomy 18p may also contribute to clonal proliferation due to the loss of putative tumor suppressor genes. Recently, the l(3)mbt-like 4 (L3MBTL4) gene located on $18 \mathrm{p}$ has been proposed to function as a tumor suppressor gene in breast cancer [8]. However, this candidate region and gene should be further evaluated for its role in carcinogenesis.

The prognostic effect of an extra 1q chromosome in myeloid disorders has been variable. While the presence of the $\operatorname{der}(1 ; 7)(q 10 ; p 10)$ translocation was reported to correlate with leukemic transformation and poor prognosis in MDS $[9,10]$, the $\operatorname{der}(\mathrm{Y}) \mathrm{t}(\mathrm{Y} ; 1)(\mathrm{q} 12 ; \mathrm{q} 12)$ translocation does not lead to a poor prognosis [11]. For cases harboring a $\operatorname{der}(1 ; 18)$ (q10;q10) translocation, the prognostic implications were also variable (Table 1 ). The MPD case showed a very stable clinical course for 2 years [3]. Similarly, the ET case also showed a relatively stable treatment progress. However, the RAEB case displayed an aggressive clinical course and the patient died just 1 month after the initial presentation [3]. In contrast, our case showed a very indolent clinical course. Although our case was diagnosed as having MDS-U just a few months ago, there is a distinct possibility that this patient already had MDS 3 years ago, based on the persistent pancytopenia. This supposition sufficiently supports the indolent progression of the MDS-U with the $\operatorname{der}(1 ; 18)(\mathrm{q} 10 ; \mathrm{q} 10)$ translocation.

In conclusion, we report a rare case of MDS-U with a $\operatorname{der}(1 ; 18)(\mathrm{q} 10 ; \mathrm{q} 10)$ translocation showing a very indolent clinical progress. Although all but one of the previous cases showed a mild clinical presentation, the prognostic implications of the $\operatorname{der}(1 ; 18)(\mathrm{q} 10 ; \mathrm{q} 10)$ translocation cannot be extrapolated at this point due to the very small number of cases. Therefore, the prognostic significance as well as phenotypic variance of the $\operatorname{der}(1 ; 18)(\mathrm{q} 10 ; \mathrm{q} 10)$ translocation have to be determined through the collection and analysis of further cases.

Jung-Sook Ha, Dong-Suk Jeon

Department of Laboratory Medicine, Keimyung University School of Medicine, Daegu, Korea

Correspondence to: Jung-Sook Ha Department of Laboratory Medicine, Keimyung University School of Medicine, 56, Dalsung-ro, Joong-gu, Daegu 700-712, Korea E-mail: ksksmom@dsmc.or.kr

Received on Feb. 13, 2014; Revised on Mar. 4, 2014; Accepted on May 15, 2014 http://dx.doi.org/10.5045/br.2014.49.2.132

\section{Authors' Disclosures of Potential Conflicts of Interest}

No potential conflicts of interest relevant to this article were reported.

\section{REFERENCES}

1. Adeyinka A, Wei S, Sanchez J. Loss of $17 \mathrm{p}$ is a major consequence of whole-arm chromosome translocations in hematologic malignancies. Cancer Genet Cytogenet 2007;173:136-43.

2. Azuma $\mathrm{T}$, Yamanouchi J, Inoue $\mathrm{K}$, et al. Derivative $(1 ; 18)(q 10 ; q 10)$ in essential thrombocythemia. Cancer Genet Cytogenet 2010;199:62-4.

3. Wan TS, Ma SK, Au WY, Chan LC. Derivative $(1 ; 18)(q 10 ; q 10)$ : a recurrent and novel unbalanced translocation involving $1 \mathrm{q}$ in myeloid disorders. Cancer Genet Cytogenet 2001;128:35-8.

4. Hussein K, Huang J, Lasho T, et al. Karyotype complements the International Prognostic Scoring System for primary myelofibrosis. Eur J Haematol 2009;82:255-9. 
5. Gangat N, Strand J, Lasho TL, et al. Cytogenetic studies at diagnosis in polycythemia vera: clinical and JAK2V617F allele burden correlates. Eur J Haematol 2008;80:197-200.

6. Diez-Martin JL, Graham DL, Petitt RM, Dewald GW. Chromosome studies in 104 patients with polycythemia vera. Mayo Clin Proc 1991;66:287-99.

7. Rowley JD. Abnormalities of chromosome 1 in myeloproliferative disorders. Cancer 1975;36:1748-57.

8. Addou-Klouche L, Adelaide J, Finetti P, et al. Loss, mutation and deregulation of L3MBTL4 in breast cancers. Mol Cancer 2010; 9:213.

9. Caramazza D, Hussein K, Siragusa S, et al. Chromosome 1 abnormalities in myeloid malignancies: a literature survey and karyotype-phenotype associations. Eur J Haematol 2010;84:191200.

10. Hsiao HH, Ito Y, Sashida G, Ohyashiki JH, Ohyashiki K. De novo appearance of $\operatorname{der}(1 ; 7)(q 10 ; p 10)$ is associated with leukemic transformation and unfavorable prognosis in essential thrombocythemia. Leuk Res 2005;29:1247-52.

11. Michaux L, Wlodarska I, Vellosa ER, et al. Translocation (Y;1)(q12;q12) in hematologic malignancies. Report on two new cases, FISH characterization, and review of the literature. Cancer Genet Cytogenet 1996;86:35-8.

\section{Simultaneous presentation of $J A K 2$ V6I7F mutation-related essential thrombocythemia and B-cell chronic lymphocytic leukemia}

TO THE EDITOR:The simultaneous development of JAK2 mutation-related essential thrombocythemia and B-cell CLL is very rare in the context of contemporary myeloid and lymphoid malignancies - until 2012, only 8 such cases had been reported. Moreover, the myeloproliferative neoplasm lymphoid/plasmacytoid association has not been evaluated in a systematic scientific manner, and therefore, the pathogenesis of this condition remains unclear. We emphasize that further studies are needed to understand the physiopathology underlying the simultaneous development of these two diseases that have markedly different clinical, prognostic, and therapeutic characteristics.

A case of simultaneous development of polycythemia vera and CLL was first reported in 1953 [1]. In certain hematological malignancies, the involvement of two different cell lineages is possible, such as in the case of chronic myeloid leukemia in the blast crisis phase, which can evolve into acute lymphoblastic leukemia. Furthermore, in mastocytosis, although rare, more than $30 \%$ of cases show an association with myeloproliferative neoplasm (MPN) and/or myelodysplastic syndrome (MDS) [2]. The coexistence of CLL or lymphoma with a solid neoplasm, such as prostatic or intestinal cancer, has also been reported. However, the simultaneous development of Philadelphia-negative ( $\mathrm{Ph}-)$ MPN and CLL is uncommon.

We report the case of a 67-year-old Caucasian woman, who presented with leukocytosis (WBC count: $20 \times 10^{9} / \mathrm{L}$ ), lymphocytosis (lymphocytes: 59\%; absolute lymphocytes: $11.8 \times 10^{9} / \mathrm{L}$ ), and thrombocytosis (platelet count: $725 \times 10^{9} / \mathrm{L}$ ). She had no significant previous illnesses. She worked as a ceramist and led a healthy lifestyle, involving regular physical activity; she had a normal body mass index and did not smoke. The physical examination indicated normal findings, and revealed no superficial lymphoadenopathy. Abdominal ultrasonography and chest radiography also showed no evidence of lymphoadenopathy and/or organomegaly. Examination of the bone marrow aspirate (Fig. 1A), as well as the bone marrow biopsy specimen, showed more than 30\% infiltration; the cells mainly comprised small lymphocytes with scant cytoplasm in the interstitial and paratrabecular regions (Fig. 1B). On immunohistochemical analysis, the lymphoid immunophenotype showed antigenic positivity for CD5 (Fig. 1C), CD20, CD23, and CD79a, whereas zeta-chain-associated protein kinase 70 (ZAP-70) assay yielded negative results. Megakaryocytosis was also noted, with large dysplastic megakaryocytes with hyperlobated nuclei (Fig. 1D), megakaryocytes with naked nuclei, and micromegakaryocytes. Bone marrow fibrosis was not present.

In both the bone marrow aspirate and the peripheral blood samples analyzed by using flow cytometry, we identified a lymphoid population of CD19+, CD5+, CD20+, and CD23+ cells with clonal restriction for the "kappa" light chain, belonging to the IgD surface immunoglobulins. Based on the exclusion criteria, "monoclonal B-cell lymphocytosis" was ruled out [3]. Given the morphological characteristics of the megakaryocytes, as well as the thrombocytosis, we tested for the JAK2 mutation, and its presence was confirmed. We did not assess the clonality of the JAK2 mutation in the sorted CD5+/CD19+ CLL cells. In the peripheral blood, fluorescence in situ hybridization indicated negative results for $B C R / A B L$ translocation.

The diagnostic criteria were suggestive of simultaneous myeloid and lymphoid lineage involvements, which represented the simultaneous presence of two neoplastic diseases - a JAK2 mutation-related essential thrombocythemia (ET) and a B-cell CLL. Regarding the myeloid involvement, taking into account the patient's high-risk stratification (age $>60$ years, even if the patient has no clinical history of thromboembolic or cardiovascular disease), we started the patient on cytoreductive therapy with hydroxyurea (500 $\mathrm{mg} /$ day) plus low-dose aspirin [4]. Instead, for the simultaneous lymphoid involvement, considered to be a CLL Binet stage A, without comorbidities, we adopted a "wait and watch" approach. The first follow-up after diagnosis showed that the patient's platelets had decreased to $400 \times 10^{9} / \mathrm{L}$, and her lymphocytosis persisted without aggravated leukocytosis. The physical examination revealed no enlarged lymph 